\title{
IMIGRANTES CALABRESES E RELIGIÔES AFRO-BRASILEIRAS NO RIO GRANDE DO SUL
}

\author{
Ari Pedro Oro*
}

A imigração italiana no Rio Grande do Sul, patrocinada ou incentivada pelo governo brasileiro, teve início em 1875 e foi destinada a zona rural da Província. Há indícios, porém, de que a 50 anos antes, alguns italianos já residiam em Porto Alegre. O seu número foi reduzido até 1850 e cresceu a partir de 1860. Provinham, sobretudo, do sul da Itália, principalmente da Calábria. Na capital da Província, formavam um grupo social relativamente fechado, o que contribuía para que sustentassem determinados traços da sua cultura de origem e não perdessem o contato com o seu "paese". 1

Morano Calabro é a cidade de origem da maioria dos meridionais que aqui chegaram num processo de imigração espontânea e que se estendeu, com alguns intervalos, até cerca de 1960 . Nos dias atuais, cerca de seis mil moraneses, incluindo seus descendentes, residem em Porto Alegre. ${ }^{2}$

Tradicionalmente, e mesmo na atualidade, as ocupações preferenciais dos meridionais italianos foram os açougues, barbearias, sapatarias, alfaiatarias, confeitarias, casas de loteria e ramos de diversões públicas como cinema, restaurantes e cafés. No entanto, uma das ocupações inesperadas de alguns desses imigrantes é o ofício de agentes religiosos das religiōes afrobrasileiras, chamados "Pai-de-Santo", ou "Mãe-de-Santo". É, por enquanto, difícil estimar a sua abrangência neste nível, e mesmo quantos participam dessas religióes como simples fiéis. É certo que o seu número não é elevado. Mesmo assim é significativo, do ponto de vista sócio-antropológico, uma vez que são indivíduos sustentado pelos tradicionais participantes dessas religiøes mediúnicas.

Embora não se trate de um fenômeno original ${ }^{3}$, procuramos compre- 
ender as razões que levaram alguns meridionais italianos a ingressarem em tais religiøes, e que sentido possui para eles essa nova identificação sócioreligiosa. Os dados foram obtidos através de observaçðes participantes em "terreiros" 4 por eles freqüentados e do levantamento da história de vida de cinco calabreses e de três descendentes da primeira geração, que participam normalmente dessas religiбes. Para essa exposição selecionamos três histórias de vida, por serem relevadoras de algumas constâncias, a saber: de Maria, 53 anos, 33 dos quais vividos no Brasil e há 26 anos Mãe-de-Santo da religião umbandista; de Luiz, filho de Maria, 29 anos e Pai-de-Santo das religiôes Batuque e Umbanda, e de Carlos, 72 anos, filho de imigrante calabres e há 40 anos participante das religióes afro-brasileiras. ${ }^{5}$

Antes de analisarmos a história de vida desses personagens, faz-se necessário traçarmos um rápido quadro das religiōes afro-brasileiras existentes no Rio Grande do Sul.

\section{As religiões afro-brasileiras no Rio Grande do Sul}

No RGS, como de resto em todo o Brasil, as religióes afro-brasileiras podem ser associadas a duas tendências, uma representando mais o Brasil, outra mais a África. Trata-se da Umbanda e do Batuque, respectivamente. Nesta última, predominam elementos mágicos, mitológicos e simbólicos da tradição africana. Na Umbanda, a África deixa de se constituir na principal fonte de inspiração sagrada. Por isso mesmo, ela reivindica um caráter nacional, tem consciência da sua brasilidade ${ }^{6}$, em suma, constitui uma "religião brasileira".?

\subsection{A Umbanda}

A Umbanda é uma religião relativamente nova. Surgiu na década de 1930, no momento em que se consolidou a implantação de uma sociedade urbana, industrial e de classes, sobretudo no sudeste e no sul do Brasil. É justamente nestas regiōes que "intelectuais" de orientação kardecista, que operam com elementos de origem afro-brasileira, iniciam a codificação da religião. Este movimento R. Ortiz chama de empretecimento da ideologia kardecista. ${ }^{8} \mathrm{~A}$ ele se associa um outro, apontado por R. Bastide, o do embranquecimento da cultura negra. ${ }^{9}$

É a partir desse duplo movimento que surge a religião umbandista como uma religião de síntese, de práticas e de crenças oriundas de horizontes diferentes, sobretudo africanos, indígenas, católicos e espíritas. 
O panteão da Umbanda é formado por algumas divindades de origem africana que nunca "encarnaram" os orixás, e por entidades que já passaram por este mundo: os "caboclos", ou seja, os índios, os "pretos-velhos", isto é, ex-escravos africanos das senzalas, e as crianç?s, relacionadas com Cosme e Damião.

Há terreiros que realizam festas, obrigaçбes e oferendas aos Exús, isto é, aos espíritos imperfeitos, "marginais" que habitaram na terra. Tais práticas estão diretamente ou indiretamente relacionados com a "magia negra", e são denominados de Quimbanda, ou "Umbanda Cruzada", ou "Linha Cruzada". Enquanto a Umbanda é tida como a prática do Bem, a quimbanda seria a prática do Mal. ${ }^{10}$ Esta última se apresenta como a dimensão oposta da primeira; ela é a sua imagem invertida. ${ }^{11}$

\section{2. $O$ Batuque}

Batuque é o nome dado, no RGS, às cerimônias africanas de origem e de influência sobretudo Gêge-Nagó, mas também ljecha, Cambinda e Oió.

A estrutura das cerimônias é, como notou R. Bastide, semelhante a do Candomblé da Bahia ${ }^{12}$, a ordem da invocação dos deuses variando segundo a linha étnico-cultural. Seus rituais se centralizam nos orixás. Estes presidem a vida da comunidade, suas ocupaçōes habituais, suas necessidades mais prementes, ou as intempéries e cataclismos da natureza. Por exemplo, Bará é o orixá dos caminhos, Ogum é guerreiro, Iansa é a deusa dos ventos e das tempestades, Xangô é o justo Juiz, Odé é o deus da caça, Ossanha protege contra doenças internas, Xapana protege contra doenças externas, Bêji é o protetor das crianças, Oxum é a deusa das águas doces, da riqueza e do amor, Iemanjá é a deusa das águas em geral, especialmente a salgada, e Oxalá é o pai de todos.

Desde os primeiros tempos, os escravos e seus descendentes associaram os orixás aos santos católicos num processo sincrético que perdura até os dias atuais. No Rio Grande do Sul, o sincretismo atual mais usual aproma Bará a Santo Antônio e São Pedro, Ogum a São Jorge, Iansã ou Oió a Santa Bárbara, Xangô-Aganju (jovem) a São Miguel Arcânjo, Xangô-Godô (velho) a São Jerônimo, Odé a São Sebastião, Otim a Sana Efigênia, Ossanha a São José, Xapañ (jovem) a São Lázaro e a São Roque e Xapanã (velho) a Nosso Senhor das Chagas, Oxum a Nossa Senhora da Conceição, Iemanjá a Nossa Senhora dos Navegantes e Oxalá a Cristo ou ao Espírito Santo. ${ }^{13}$ 
A Umbanda é uma religião que se considera mais evoluída do que o Batuque ou outras formas de religião que possuem acentuada herança africana. Sinal desta sùa auto-concepção de religião mais adiantada é a inexistência de rituais de sangue, de sacrifício de animais, práticas taxadas de "barbarismo", de "atraso mental", de "ignorância". Outro sinal são os valores de classe média que zelam, como a "limpeza" pessoal e dos locais onde se desenrolam os rituais, e a boa apresentação. A própria bebida, que é oferecida às divindades, é reveladora do grau de evolução espiritual, e, conseqüentemente, da posição social dos membros do grupo. Em terreiros de classe inferior, as entidades bebem cachaça, bebida do povo; elas bebem vinho ou champagne em terreiros de classe média. Ainda, o discurso umbandista se quer científico; por isso palavras como "ego", "inconsciente", "energia", "força vital", são seguidamente repetidas.

Nota-se que, neste caso, " . . . evoluir significa não somente se aproximar da cultura branca, mas assemelhar-se ao branco burguês ou pequeno burguês". ${ }^{14}$

Apesar dessas diferenças, ambas as religiões apresentam elementos comuns que permitem, conseqüentemente, classificá-las como religiōes afro-brasileiras. Há nelas o fenômeno da possessão, uma hierarquia fortemente estabelecida entre os Pais e Mães-de-Santo de um lado e os Filhosde-Santo de outro lado, estes possuem santos de cabeça, de corpo e de passagem; o sincretismo religioso é uma realidade tanto no Batuque quanto na Umbanda.

\section{Os filhos dos deuses}

\subsection{O destino implacável de Maria}

Maria nasceu em Mormano, província de Cosenza, na Calabria; tem 53 anos de idade. É oriunda do meio rural. Casou-se aos 18 anos e aos 19 emigrou para Porto Alegre, acompanhando seu marido, cujo pai aqui se encontrava desde 1925. Quando aqui chegaram, em 1953, seu sogro já estavamorto há seis meses. Começou, então, para Maria, uma vida de sacrifícios. Sem parentes, sem saber se comunicar em português, sem emprego, ela foi alojada, provisoriamente, com seu marido, numa peça da casa da sua sogra brasileira. Depois se transferiram para uma xácara de propriedade de Antônio, um calabrês.

Tendo já uma filha e estando novamente grávida, Maria se separou do seu marido. Luiz, seu segundo filho, não havia completado dois meses, 
quando adoeceu gravemente. Como o tratamento não dava resultado, Maria seguiu o conselho da esposa de Antonio, uma brasileira. Levou-o a uma senhora "bem pretinha", filha de Xangô. "Se a senhora curar o meu filho, eu prometo que meu filho, quando tiver a idade de seguir uma religião, seguirá a sua religião", disse Maria à Mãe Guiomar. Três dias após, Maria levou Luiz, curado, para casa de Antônio.

Aborrecida por não trabalhar, Maria foi ao consulado Italiano, contou a sua história, e a carta de apresentação que obteve do cônsul facilitou para que obtivesse o emprego na fábrica de tecelagem Matarazzo. Ali trabathou durante três anos, saindo quando essa empresa se transferiu para São Paulo. Nesse tempo, Maria morou numa peça da casa de uma patrícia. Durante vários meses dormiu no chão, cobrindo-se com jornais. Trabalhou em seguida, durante seis meses, como camareira diarista do Hotel Plaza, saindo para ser responsável da cozinha do SESC. Ali trabalhou 18 anos, de 1960 a 1978, quando passou a se dedicar inteiramente à religião como Mãe-deSanto. Morava, nesta ocasião em casa alugada.

Sem revelar a seu filho o segredo da promessa, Maria aconselhava-o a visitar centros de Batuque. Até os 14 anos ele repetia que queria ser padre. Mas, aos 15 anos, já participando da Umbanda, Luiz iniciou sua preparação no Batuque. Foi somente após ter feito o "primeiro chão", que Maria narrou-lhe o evento da sua cura, quando pequeno, e a promessa feita.

Hoje seu filho é seu Pai-de-Santo. "Aqui dentro o Luiz não é meu fitho. Ele é meu Pai-de-Santo. Dentro da religião, ele deixou de ser meu fitho". Esta declaração revela que se instaura entre Maria e Luiz uma relação paradoxal, que implica numa reversão de status. Com efeito, aos olhos de Maria Luiz é seu filho (que protege, ajuda, aconselha, repreende, educa), e, ao mesmo tempo, ele é seu pai (que a protege, a ajuda, a aconselha, a repreende). $\mathrm{O}$ mesmo se passa com Luiz em relação a sua mãe; mas, num processo inverso; ela é vista como sua mãe na esfera do profano e como sua filha no campo do sagrado. Trata-se de uma dupla identidade contrastante. Esta inversão de papéis, que implica em relações de poder, nem sempre é clara entre ambos, acarretando invariavelmente situaçбes conflitantes.

Maria não esconde a discriminação e a marginalização que sofreu, por parte dos seus patrícios, ao optar pela religião afro-brasileira. Relata que enquanto os brasileiros assimilaram bem este fato, muitos calabreses, com os quais convivia, passaram a estigmatizá-la de batuqueira, cigana, bruxa. Esclarece também que nenhum calabrês participou assiduamente da sua casa de religião, embora fosse comum ver ali um certo número deles para encomendar um serviço, jogar búzios, cartas, etc.

Analisando hoje a sua vida pregressa, Maria está certa de que tem uma missão especial a cumprir neste mundo como Mãe-de-Santo e filha de 
Iemanjá. Seu destino estava traçado e por isso tinha que vir para o Brasil, porque, diz ela, "os santos queriam trabalhar e precisavam de mim".

"Por isso que eu digo: eu pra mim foram os santos que me trouxeram pra cá, porque eles queriam trabalhar e la na Itália não tinha religião. La na Itália é só católico. Então fizeram de tudo, viajar 29 dias, o sogro falecido, a doença do Luiz, tudo isto pra mim entrar na religião. Eu imagino que seja isto. Esta é a minha verdadeira missão. Vê o que é uma missão a cumprir!".

Na Calábria, Maria era católica fervorosa, filha de Maria. Ia todos os domingos à "missa das 10 ", com livro, terço e véu, confessava e comungava. Gostava de rezar a Nossa Senhora e a São Miguel Arcanjo, que correspondem a Iemanjá e a Xangô-Aganju no Batuque. Ela vê neste fato novo sinal do seu destino implacável.

Revela ainda que seu dom especial já havia se manifestado na Itália. Tendo oito anos de idade e sua avó estando no leito há três anos, Maria perguntou a sua mãe se queria ver a avó morta. Disse-lhe que em 24 horas ela iria morrer. Fez uma cruz com dois pedaços de taquara e colocou-a sob seu travesseiro, vindo a avó a falecer. Evidentemente que sua mãe, zangada, chamou-a de bruxa e de cigana.

Infere-se, pelas declaraçб̃es de Maria, que ela foi criada num meio social que não fazia uma separaçao clara entre o sagrado e o profano, o primeiro sendo o fundamento do segundo, e que acreditava em espíritos errantes, em "simpatias", em ações mágicas e supersticiosas para obter bem estar, para se proteger contra o mal, doenças, etc. Ela relatou várias oraçб̄es contra o "olho-grande", contra a inveja, contra dores localizadas no corpo, contra os maus espíritos, lobisomem, etc. Afirma, inclusive, ser detentora de três oraçð̄es sigilosas, uma contra o "olho-grande", outra contra a inveja e outra contra as verminoses, que the foram transmitidas por sua avó, antes de morrer. Ela poderá revelá-las também somente no fim da sua vida.

É preciso assinalar que Maria conhece a maior parte das oraçôes contra os mais variados males e circunstâncias registradas no livro "Magia, miti e credenzi popolari", acerca dos Albanezes da Itália, de A. Bellusci. A religião praticada aqui no Brasil por Maria nđo somente se asemelha a desses tipos de crenças populares e açбes mágicas que trouxe da Itália, mas ela aprofunda-se, radicaliza-as. Isto significa que, de certo modo, Maria possuía uma pre-disposição religiosa, propícia para compreender e assimilar as religiøes afro-brasileiras.

No entanto, Maria Continua a se considerar católica.

"Eu não deixo nunca de ser católica. Se tiver que rezar o terço eu rezo. Todo dia, de noite, quando vou me deitar, eu rezo na minha língua". 
Parece que o sincretismo religioso, elaborado por Maria, é o de correspondência, em certos aspectos, da religião católica com as religióes afrobrasileiras, e o de superposição, mais do que de justaposição dessas religiøes, em outros aspectos. Assim, ao nível das divindades, nota-se uma correspondência perfeita dos orixás com os santos católicos. A sua Yemanjá é branca, com cabelos longos e loiros. Xangô-Godô é o velho São Jerônimo, sentado com um livro na mão. Ogum é o conhecido São Jorge, sobre o cavalo, matando o dragão com a lança. No entanto, a homologia não é completa em sua mente. Reconhece que os rituais de ambas as religiōes são diferentes, e, sobreetudo, na religião católica, os santos não vem ao mundo, isto porque "o padre não aceita que os santos cheguem; não dá permissão para o espírito vir no mundo".

Apesar de continuar a recitar as rezas católicas, é diante do "pegi", altar do Batuque, que Maria se dirige quando tem problemas sérios para resolver. Ali ela conversa com o Pai Xangô, com a Mãe Iemanjá, ela pede ajuda, conselhos, desabafa, xinga, agradece. Conforme o problema a resolver, ela se dirige aos Exus, sobretudo ao seu Tiriri, "que é mais rápido do que os velhos"; ele abre caminhos, sempre lhe atende. Ela mantém com os orixás e as entidades uma relação pessoal, íntima e afetiva. Eles desempenham o papel de conselheiros, amigos, protetores. Eles lhe dão segurança. Eles substituem os pais e o companehiro que ela não teve em terra estrangeira. Por isso mesmo, toda a sua vida gira em torno da "religião", como ela diz (revelando assim a importância que atribui as religiōes afro-brasileiras), que se tornou para ela, aqui no Brasil, o fundamento da sua vida. Ademais, ela vê "a religião" como uma "escola de vida" e como uma arma de que dispõe para lutar contra todos os problemas: "A religião foi uma escola para mim. Ela me ensinou a viver, a brigar, a sorrir; me ensinou a ser triste e ser alegre. Ela é uma aula para mim. Me tirou aquela parte de ser boa. A religião me ensinou o mal e o bem. Como devo reagir ...".

Em razão da segurança e do bem-estar que a religião afro-brasileira the proporciona, Maria considera-a mais evoluída do que o catolicismo. Conseqüentemente, segundo ela, "o Brasil é mais adiantado do que a Itália porque aqui tem religião e la não; ao menos no meu tempo não tinha".

\subsection{Xangô, o melhor dos orixas}

Luiz tem 29 anos, é ligeiramente gordo. Como Pai-de-Santo, dedicase em tempo integral a religião. Demonstra ter muita segurança no que faz. É fundamentalmente da prestação de serviços religiosos a pessoas externas ao grupo, serviços estes também realizados por sua mãe, que ambos levan- 
tam os fundos necessários para viver e para custear as despesas com a religião. ${ }^{15}$ Os que the procuram são geralmente pessoas da classe média baixa, mas também de outras camadas sociais.

Luiz ingressou primeiramente na Umbanda. Durante um ano, quando completou 17 anos de idade, residiu na casa da sua Mãe-de-Santo, Guiomar de Oxum. Mais tarde, foi, ali mesmo, iniciado também no Batuque. Foi uma aprendizagem intensiva. Com 18 anos começou a trabalhar como Pai-de-Santo, na casa da sua mãe Maria. Cada um tinha os seus Filhos-deSanto. Essa situação durou um ano, pois Luiz se transferiu para a casa em que se encontra nos dias atuais, onde trabalha com Batuque, Umbanda e Linha Cruzada. Não esconde porém a sua paixão pelo Batuque.

Luiz confessou que entrou em conflito interno, quando ingressou no Batuque, em razão da sua formação católica. Hoje, diz brincando que se considera "católico, apostólico, romano e batuqueiro". Vê semelhanças e diferenças entre o Batuque e o Catolicismo; porém atribui maior importância a primeira religião.

Nas entrevistas, este Pai-de-Santo revelou estar à procura da sua identidade pessoal. Ouçamo-lo falar :

"Nasci no Brasil, mas meu sangue não é brasileiro. Eu só sou brasileiro porque nasci no Brasil, mas para mim é como se tivesse nascido na Itália porque eu fui feito por um pai e uma mãe italianos. Eu não tenho nada a ver com o Brasil. Não tenho nenhuma gota de sangue brasileiro (...). Sou brasileiro e sou italiano, e agora? Sou brasileiro porque moro no Brasil, e sou italiano porque tenho sangue italiano".

O elemento religioso é outra variante sobre a qual Luiz se baseia para construir a sua identidade.

"Pela religião eu sou africano, porque minha religião não nasceu no Brasil. Se fosse escolher entre conhecer um país do exterior seria em primeiro lugar a Äfrica. Na Itália está o meu sangue mas na África está a minha vida. Minha vida é minha religião. Quero ver donde veio Xangô, o melhor dos orixás".

Seu santo de cabeça é Xangô-Aganju. Este é concebido como moço e fogoso, viril e corajoso. A identificação com este orixá lhe permite ter um melhor ajustamento da personalidade, na medida em que, nas noites de rituais, ele assume, de certa maneira, papel oposto ao da vida quotidiana. Ele se torna o grande Deus do trovão, sedutor das mulheres que se prostam aos seus pés. 


\subsection{Carlos, também filho de Xangô}

Seu avô era natural de Castrovillari. Emigrou para São Paulo para trabalhar nos cafezais. Regressou a Calábria por volta de 1887, quando seu pai nasceu. Este, sozinho, retornou ao Brasil quando completou doze anos de idade e fixou residência em Porto Alegre, "onde foi amparado por patrícios".

Carlos nasceu em 1914. Quando criança ajudava seu pai nas lides do açougue. Recebeu instrução em colégio católico. Cursou dois anos de medicina e outro tanto de direito. Em 1938, ingressou na polícia civil como inspetor. Em 1939, casou com uma brasileira. Não teve filhos.

Foi como policial, acompanhando colegas nas rondas noturnas, que Carlos conheceu o terreiro da mãe Geralda e assim ingressou na Umbanda, sendo filho de Xangô. Quando pequeno, porém, sua mãe, brasileira, já o havia levado em terreiros.

"Gostei, achei a velhinha muito humana, nunca fez mal pra ninguém, aquilo era uma velhinha adorável. Comecei a conversar com ela, meu filho pra cá, meu filho pra lá. Um dia ela disse que eu era filho dela e está acabado o assunto".

Freqüentou ativamente a casa, durante cerca de 20 anos, até que a Mãe-de-Santo morreu. Depois, a participação nos rituais se tornou menos intensa. Recrimina a competição existente hoje em dia entre as casas de religião e sobretudo a importância que o aspecto econômico assumiu nelas, nas últimas décadas.

Ao ouvir Carlos efetuar o relato da sua vida, ficamos sabendo de alguns aspectos interessantes sobre os costumes de um grupo de calabrezes de Porto Alegre, entre os anos de 1925 e 1940, aproximadamente. A família de Carlos pertencia a classe média de Porto Alegre e se relacionava com patrícios da mesma posição social. Eram todos açougueiros, alfaiates, comerciantes. Conta Carlos que, todas as quintas-feiras, um grupo de cerca de 15 patrícios se reunia, na casa de um deles, para comer, cantar e jogar. Comiam comida italiana, cantavam cânticos italianos, jogavam carta e "mora". Chamavam esses encontros de reuniões, e em cada uma delas tomavam um quinto de vinho. Por isso, e por se reunirem as quintas-feiras, o grupo formava o "Clube das Quinta". Era um grupo informal de amigos que, nãoobstante, tinha um presidente, embora nunca tivesse sede própria.

Embora os calabreses se considerassem todos católicos, o informante esclarece que no seu meio havia liberdade religiosa, ninguém interferindo na vida alheia. Pessoalmente, confessa que não sentiu rejeição por participar da religiāo afro-brasileira, contrariamente à Maria, que afirmou ter sido marginalizada. 


\section{Conclusão}

Embora Maria explique a sua entrada nas religiôes afro-brasileiras como fazendo parte do seu destino, relacionando-o à missão a cumprir no Brasil; nota-se que, de fato, a sua adesão a essas religiōes está ligada a duas ordens de fatores: ao tipo de religião de que era portadora, que lhe permitiu compreender e decifrar os códigos das religiøes afro-brasileiras, e às situaçōes concretas por que passou nos primeiros anos de sua vida em Porto Alegre, enquanto imigrante.

De fato, a informante proveio do meio rural do sul da Itália, onde, segundo A. Bellusci e R. Cipriani ${ }^{16}$, paralelamente a doutrina da religião cristã, há uma "religião do povo", que passa de geração em geração, e que é composta de práticas mágicas e supersticiosas, contos e lendas, usos e costumes, ritos e cerimônias, que visam defender o homem das influências negativas e atrair as influências positivas das forças ocultas e que oferecem, igualmente, meios para conhecer o futuro ou saber coisas ocultas.

Por outro lado, a entrada de Maria nas religióes afro-brasileiras foi indiretamente condicionada pela sua situação de marginalidade social, decorrente das grandes dificuldades que enfrentou sozinha em terra estranha। Novamente, comprova-se aqui a constatação de R. Bastide, para quem o branco imigrante que adere as religiøes afro-brasileiras é marginal, socialmente falando como o preto. ${ }^{17}$ Mas se a situação de marginalidade, enquanto tal, condiciona as pessoas a procurarem as religiōes afro-brasileiras; há, na história dos seus fiéis, um momento decisivo da conversão, relacionado, no mais das vezes, como no caso de Maria, a razões terapêuticas: procura-se tais religióes porque se está doente e permanece-se nelas porque se foi curado.

Carlos também revelou ter ouvido do seu pai relatos de crenças populares do "Mezzogiorno" semelhantes às que encontrou nas religiøes afrobrasileiras. Mas, parece que no seu caso foi sobretudo o carisma de mãe $\mathrm{Ge}$ ralda que o atraiu, assim como a outros policiais, para dentro dessas religiōes, não deixando de ser irônico, pois aqueles, cujo dever era vigiar, quando não reprimir tais manifestações religiosas, se tornaram seus simpatizantes e freqüentadores.

Luiz, por sua vez, foi, de alguma forma, desde pequeno, influenciado, senão condicionado, por sua mãe, em razão da promessa feita, para freqüentar as religiőes afro-brasileiras. Não é de se estranhar pois se com 18 anos de idade ele já exercia a profissão de Pai-de-Santo

A participação de Maria e de seu filho em terreiros permitiu-lhes a criação de novos laços sociais e de uma relativa integração numa parcela da sociedade brasileira, já que a própria freqüência em terceiros se constituiu, 
para eles, ao menos parcialmente, numa barreira para obter uma melhor inserção social na sociedade calabresa. Já Carlos que transita desde pequeno num outro nível social e que sempre conviveu com pessoas de sua origem étnica, participou ativamente da religião somente enquanto a sua mãe carismática viveu, relaxando após provavelmente porque encontrou no grupo social ao qual estava integrado parte da satisfação procurada no agrupamento religioso.

Para os dois primeiros personagens mais do que para o terceiro, o apego à religião, ao invés de se constituir numa fuga para o imaginário se apresenta como o fundamento das suas vidas individuais e como o viés do seu relacionamento social. Tudo o que fazem passa pela religião Nela, economia, sociedade, política afetividade estão implicadas. Foi através dessa religião, rica em atividades mágicas e que permite um contato direto e livre do indivíduo com os santos, que eles conquistaram seu espaço enfrentaram todos os problemas surgidos e venceram até o presente Além de encontrarem nela a necessária proteção e segurança, conseguiram se elevar socialmente. possuindo um centro de religião de nível sócio-econômico médio. $^{18}$

Sugerimos que os imigrantes ou seus descendentes, que se voltam e permanecem nas religióes afro-brasileiras o fazem porque encontram nelas apoio, consolo solução para os problemas os mais variados, visto terem dificuldade de acesso e de participação em outras instituições e situações favorecedoras de alívio e de bem estar, como hospitais sindicatos partidos políticos, trabalho digno etc.

Mas os italianos ou seus descendentes que seguem as religiôes afrobrasileiras dificilmente renegam a religião católica Eles passam a se valer de ambas as religiōes mais concretamente da primeira para tudo quanto diz respeito aos sofrimentos desejos ambigüidades do mundo como acidentes doenças e morte, (pois estas religiōes atuam no espaço interior do sofrimento e da magia), e da segunda para os eventos relacionados com espaços exteriores de legitimação social como batismo casamento, formatura, enterros. Como muitos brasileiros. muitos italianos e seus descendentes podem, portanto ser, ao mesmo tempo, católicos e adeptos de religiões afro-brasileiras ${ }^{19}$

\section{NOTAS}

Com algumas adaptações, este trabalho foi objeto de uma comunicação apresentada no Encontro sobre Imigração Calabresa em Porto Alegre que teve lugar na PUCRS, no mês de outubro de 1986. 
Três alunos do Curso de Ciências Sociais da PUCRS ajudaram no levantamento dos dados aqui expostos São eles Cláudia Solares, Maria Helena Nunes da Silva e Clóvis da Silva Dalsotto.

${ }^{1}$ A historia da imigração calabresa no Rio Grande do Sul está sendo pesquisada pela professora Nuncia Santoro de Constantino, que prepara sobre este tema, uma tese de doutorado, na USP. Para uma rápida idéia das razões da imigração espontânea desses meridionais a Porto Alegre, ver: Nuncia Santoro de Constantino "Italianos em nú-

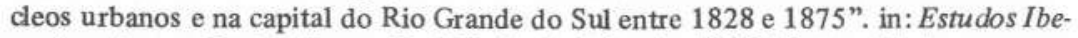
ro-A mericanos Porto Alegre, V. XII, N. 1, julho de 1986 "Outra cidade no pensamento imigrantes moraneses". in. Presença Literária 1988. Porto Alegre, Nova Dimensão 1988, e "Italianos no Rio Grande do Sul' . in. I Ciclo de Palestras sobre a historia do Rio Grande do Sul'. Porto Alegre, 1986.

"“A tradição revela, escreve N. S. de Constantino, que há mais moraneses em Porto Alegre do que na cidade de Morano o governo do Estado promulgou decreto, em 1975 , declarando "irmãs" as duas cidades e a Prefeitura Municipal veio a inaugurar uma rua denominada "Morano Calabro" (Santoro de Constantino, Nuncia. "Italianos". in Porto Alegre. Historia e Cultura"., Porto Alegre, Martins Livreiro ed., 1987, p 62).

D. de Laytano afirma que existem hoje, em Porto Alegre, seis mil moraneses, contando seus descendentes, enquanto que a Laytano. "A presença calabresa nas cidades gaúchas, principalmente em Porto Alegre". in. Veritas Porto Alegre, N. 131, setembro de 1988).

${ }^{3}$ A presença de "brancos" nas religiōes afro-brasileiras já foi objeto de estudo de parte de R. Bastide, M. I. Pereira de Queiroz, J. do Rio A. P. Oro, entre outros. (Bastide, Roger. As religiós africanas no Brasil. São Paulo, USP/L. Pioneira Ed., 2 V. 1971 Pereira de Queiroz. Maria Isaura. "Evolution et creation religieuses. les cultes afro-bresiliens". in: Diogene Paris, N. 115, julho-setembro 1981; Rio, João do. As religiбes do Rio. Rio de Janeiro, Garnier, 1960, Oro, Ari Pedro "Negros e brancos nas religiôes afro-brasileiras no Rio Grande do Sul'. in Comunicaçóes do ISER, Rio de Janeiro, B. 28, março de 1988).

4.'Terreiros", 'centros', ou "casas-de-religião', são nomes pelos quais se denominam os templos das religiðes afro-brasileiras.

${ }^{5} \mathrm{O}$ número de informantes é reduzido. Considerando-se porém as técnicas utilizadas, que permitem um real aprofundamento e privilegia a intensidade ao invés da extensividade dos dados, parece-nos que algum conhecimento pode ser alcançado sobre a problemática aqui privilegiada

A este propósito, vale a pena lembrar J. Freund, que, comentand o o método weberiano, diz ser ilusão imaginar que a quantificação, ou o método generalizante, confere maior qualitativo, ou individualizante (Freund Julien La sociologie de Max Weber. Paris, PUF, 1983).

${ }^{6}$ Ortiz, Renato. "A morte branca do feiticeiro negro'. in: Cadernos do CERU. N. 9 , São Paulo, 1976.

${ }^{7}$ Concone, Maria Helena Villas-Boas. Umbanda: uma religiáo brasileira. São Paulo, FFLCH/USP-CER, 1987.

${ }^{8}$ Ortiz, Renato. "A morte ranca do feiticeiro negro". op cit., 1976, p. 1.

${ }^{9}$ Bastide, R. As religióes africanas no Brasil. op. cit.

${ }^{10}$ Os termos Bem e Mal precisam ser relativizados.

${ }^{11}$ Ortiz, Renato. A morte branca do feiticeiro negro. Petrópolis, Vozes, 1978, pp. 79 e ss. 
${ }^{12}$ Bastide, Roger. Sociologia do folclore brasileiro. São Paulo, Anhambi, 1959, p. 245).

${ }^{13} \mathrm{Na}$ década de 1950 , a correspondência entre orixás e santos católicos era ligeiramente diferente da atual, conforme se pode depreender do estudo de Dante de Laytano. A Igreja e os Orìxás. Porto Alegre, Ed. da Comissão Gaúcha de Kolclore, S.D., p. 43.

${ }^{14}$ Ortiz, Renato. "A morte branca do feiticeiro negro", op. cit., p. 122.

${ }^{15}$ A receita mensal da casa oscilava, em setembro de 1987 , entre 15 e 20.000 cruzados,

${ }^{16}$ Bellusci, Antonio. Magia, miti e credenze popolari. Ricerca etnografica tra gli Albanesi d'Italia. Cosenza, Centro Studi e Ricerche socio-cultural " $\mathrm{G}$. Kastriota Skanderbeg", 1983; e Cipriani, Roberto. "La religiosité populari en Italie: deux recherches sur la magie et la politique dans le sud pu pays". in: Social Compass, Bruxelas, XXIII, 1976/2-3.

${ }^{17}$ Bastide Roger. Sociologia do Folclore brasileiro. op. cit., pp. 302 e 261.

${ }^{18}$ Para tanto, exploram todas as possibilidades que o mercado religioso pode oferecer, trabalhando com Batuque. Umbanda e Linha Cruzada.

$\mathrm{O}$ estado atual das nossas pesquisas não permite seguir Bastide quando afirma que "enquanto o preto procurava antes de tudo na religiâo ou na magia a ascensão social (...) o branco procura antes de tudo lucro e dinheiro" (Bastide, R. Sociologia do folclore brasileiro. op. cit., p. 303).

${ }^{19}$ Esta observação sobre a não incompatibilidade de participação dos brasileiros nas duas religióes em questão foi feita por R. da Matta (Matta, Roberto da. Exploraçóes. Ensaios de sociologia interpretativa. Rio de Janeiro, Rocco, 1986).

* Pontifícia Universidade Católica do RGS.

Curso de Pós-graduação em História.

90620 - Porto Alegre - RS. 